\title{
THE PREVALENCE OF BODY DYSMORPHIC DISORDER WITH A TENDENCY TO ANOREXIA NERVOSA IN ADOLESCENTS
}

\author{
Diona Ossy Wahyuni ${ }^{1}$ \\ Correspondence: dionaow@gmail.com \\ ${ }^{I}$ Medical Faculty Brawijaya University, Indonesia
}

Background: Anorexia nervosa (AN) and body dysmorphic disorder (BDD) are severe body image disorders that severely interfere with the daily functioning of the individual. They are separate but overlapping nosologically entities. There is a study on the tendency of wrong eating behaviour in adolescents with specifications for anorexia nervosa in Jakarta $11.6 \%$ and there is also a study at High School in Jakarta $88.5 \%$ of adolescents experience wrong eating behaviour with the specifications of anorexia nervosa. And the two largest epidemiological surveys regarding BDD, there were $2.5 \%$ women and $2.2 \%$ men. With a fairly high number of these two events, this has the potential to have a negative impact on someone's health. This study aims to discuss the impact of anorexia nervosa.

Methods: The researcher used several literature and scientific journals, which was based on 15 journals and literature, discussing a tendency to anorexia nervosa with the incidence of Body Dysmorphic Disorder and its medical emergencies.

Conclusion: There is a correlation of anorexia nervosa among teenager especially girl teenage.

Keywords: body dysmorphic disorder, anorexia nervosa, adolescents.

\section{Article History:}

Received: January 2, 2021

Accepted: February 20, 2021

Published: March 31, 2021
Cite this as: Wahyuni, D.O. The prevalence of body dysmorphic disorder with a tendency to anorexia nervosa in adolescents. Journal of Psychiatry Psychology and Behavioral Research; 2021.1:12-15.

\section{INTRODUCTION}

The level of change that occurs in adolescence is not only in attitudes and behavior but is parallel to the level of physical change, namely body shape. Rapid growth period of adolescence is marked by drastic physical changes that cause adolescents to pay close attention to their bodies, especially young women. This attention produces a view of body shape or what is called body image. Body image is the degree of individual satisfaction with himself physically which includes size, shape and general appearance. ${ }^{1}$

Body image itself is formed because of the perception of each person about the ideal body shape and what they want according to their respective thoughts. And this is also formed because of the factors that come from themselves and others. When a person considers that his physical condition is not ideal, then that individual will try to change or replace a form that he thinks is not ideal in order to satisfy the perceptions of the individual himself and indirectly fulfil the "ideal" perception according to the views of the majority of others.
Then, in journals related to body image, it is stated that body image itself can be categorized into two things, namely positive and negative body image. In a positive body image, a person may be able to perceive their body shape positively and well, appreciate their body shape and have a good level of confidence in their body. Another case in negative body image. When a person has a negative body image, one can create dissatisfaction with their body shape. And furthermore, the habit of this thinking will lead to a bad diet, for example a very little diet. Anorexia nervosa is a form of eating disorders that causes sufferers to be reluctant to increase their body weight even though their weight is below the normal body index for the average human. Anorexia nervosa itself causes sufferers to lose weight by dieting without eating and limiting the amount of food that should be a source of nutrition for the sufferer's body. ${ }^{2}$ Due to the increasing number of adolescents who are concerned about changes in body shape in themselves and experience wrong eating behaviour, all of these behaviours affect adolescent health. So, we need knowledge about the impact of clinical emergencies from this condition. 


\section{METHOD}

The researcher used several literature and scientific journals, which was based on 15 journals, literature, viewpoints and articles discussing body image disorder and its relation to eating disorders, for example anorexia nervosa and the impact of its clinical emergency.

\section{DISCUSSION}

\section{Prevalence of Body Image Dysmorphic Disorder}

The Tendency of Body Dysmorphic Disorder is a disorder that focuses on an appearance or body shape that is possibly just an imaginary (e.g., body texture and a flat nose). The tendency of Body Dysmorphic Disorder is a false belief about what is owned by him because he is not satisfied with his appearance. Body Dysmorphic Disorder is a somatoform disorder. ${ }^{3}$ Body Dysmorphic Disorder tends to develop into adolescence around 16-17 years of age, with an average onset at age 15. An individual begins to pay attention to his appearance at the age of 12 or 13 years, and his attitude will continue to develop to determine the diagnostic criteria. Some individuals may experience sudden onset of BDD. The condition can also occur in older adults who are overly concerned about their aging appearance. The occurrence of BDD is usually continuous. This disorder was slightly more experienced by women $(2.4 \%)$ than men $(2.2 \%)$ of the total adult patients. BDD is classified as a somatoform disorder (body disorder) in DSM IV. To identify and diagnose BDD. Diagnostic criteria according to the Diagnostic and Statistical Manual of Mental Disorders 4th edition can be seen in Table 1 .

Table 1. Diagnosis criteria according to DSM IV ${ }^{4}$

\begin{tabular}{|l|l|}
\hline No. & Criteria \\
\hline 1. & $\begin{array}{l}\text { Preoccupation with a perception of disability in } \\
\text { appearance. if a minor physical abnormality is found, } \\
\text { the patient will pay attention to excess }\end{array}$ \\
\hline 2. & $\begin{array}{l}\text { Preoccupation causes significant clinical suffering or } \\
\text { failure in social, work or other important matters }\end{array}$ \\
\hline 3. & $\begin{array}{l}\text { Preoccupation should not be confused with other } \\
\text { mental disorders (for example, dissatisfaction with } \\
\text { body shape and size in anorexia nervosa) }\end{array}$ \\
\hline
\end{tabular}

According to Erikson's view, a teenager is at a stage of a crisis of identity, this encourages adolescents to seek their identity (self-identity), by realizing their desire to become a "perfect" individual, intellectually, personally, or in his physical appearance. To be able to look attractive and attractive to the opposite sex, one of the efforts is to try to have an ideal body shape, for example by adjusting the diet. However, often many adolescents are haunted by worries and worries that they will experience failure from these efforts.

Because they want to avoid themselves so that they are not overweight. This excessive worry causes individuals to strictly diet or abstain from eating habits. If they feel hungry, they don't eat immediately, but they are allowed to stay hungry. If he feels that he has succeeded in not eating, then he will feel proud or happy or even satisfied. Thus this is done repeatedly. However, because of his ignorance of a good diet, so that it disrupts his diet, as a result, adolescents experience eating disorders, one of which is anorexia nervosa.

\section{Eating Disorder (Anorexia Nervosa)}

Eating disorders are a psychiatric disease characterized by a deviated diet related to psychological characteristics related to eating, body image and body weight Eating disorders that commonly occur in adolescents are anorexia nervosa and bulimia nervosa. ${ }^{5}$ Globally, it is known that the number of patients with eating disorders has increased since the last 50 years. There are reports that in the United States there are as many as 500,000 women who are included in the diagnostic criteria for anorexia nervosa. ${ }^{6}$

The data show that $1 \%$ of cases of eating disorders in young women in the United States suffer from Anorexia Nervosa (AN) and 4\% suffer from Bulimia Nervosa (BN) while in Norway $2.6 \%$ of adolescents suffer from Anorexia Nervosa (AN), in Italy $1,3 \%$ of teenagers suffer from Anorexia Nervosa (AN), in Cairo there are $1.2 \%$ of school children suffering from Bulimia Nervosa $(\mathrm{BN})$ and in Iran there are as many as $3.2 \%$ of school children suffering from Bulimia Nervosa (BN). ${ }^{6}$ When compared between western and non-western countries, the prevalence of eating disorders in non-western countries shows a smaller number of cases but shows an increase.

The prevalence in western countries for the incidence of anorexia nervosa in women is $0.1-5.7 \%$, for bulimia nervosa in men is $0.2-1 \%$ and in women is $0.3-7.3 \%$. In non-western countries, the prevalence of bulimia nervosa in women is 0.46 $3.2 \%$. A study states that $7.8 \%$ of respondents have a higher risk of experiencing eating disorders. ${ }^{7}$ Meanwhile, other research results reveal that $14.3 \%$ of respondents have a high risk of experiencing eating disorders. ${ }^{8}$

In Indonesia, there is still a lack of research data on eating disorders, so the prevalence of the incidence of eating disorders in Indonesia is still not known with certainty. ${ }^{9}$ This data shows that non-western countries have a lower prevalence of eating disorders but show an increase, and the lack of research data on eating disorders in Indonesia makes it very important to conduct research on eating disorders in Indonesia. Body image, biological, psychological, social, family, media, and culture were described as causing eating disorder. ${ }^{10}$ Anorexia nervosa is an eating disorder that aims to make the body thin by deliberately limiting eating and controlling it tightly. AN diagnosis is based on its behavioural, psychological and physical characteristics. The diagnostic criteria that are widely used are from the American Psychiatry Association through the DSM-IV. ${ }^{4}$ These criteria include of excessive fear of gaining weight or getting fat; reluctance to set body weight at or above the minimum normal weight according to age and height; body vision distortion (feeling he is "too fat" even though he is underweight); do not experience menstruation (amenorrhea) for at least 3 consecutive cycles.

\section{The Impacts of Anorexia Nervosa on Adolescents with Body Dysmorphic Disorder}

Based on several studies, it can be seen that the tendency of Body Dysmorphic Disorder with the tendency of Anorexia Nervosa has a significant relationship. Teens who have a tendency to BDD will be higher because the level of tendency of Anorexia Nervosa is also increasing. When examining a patient with $\mathrm{AN}$, it is very important to obtain information about vital signs such as heart rate in sleeping and standing positions, blood pressure and body temperature, checking for dryness of the skin and extremities, circulation information including the presence of bradycardia and arrhythmias, information on digestive health, and information about the 
central nervous system that may cause weight loss and vomiting. ${ }^{11}$

Suffering from anorexia can be annoying work stability of the body system so that cause some bad effects, between others: bone loss, mineral loss, low body temperature, a heart rate irregular, permanent disruption to body growth, prone to exposure osteoporosis, even bulimia nervosa. Besides, there was an even worse effect if a person is anorexic take laxatives because they are very laxatives harmful to the body. The laxative substances that will force the body secrete fluids as well as food still processed in the intestine so the nutrients are not completely absorbed. Laxatives also contains chemicals that it might get absorbed by body. Long-term use of laxative length can cause distraction permanent on the stability of the digestive system and cause the body to lack a lot nutrition. Even people with anorexia avoid eating, they have interest in food quite intensive. They cook for people else, they talk about food, and they insisted on seeing someone else eat. Anorexics have disturbing body image, consider that they're going to be interesting only when they look like skulls. They continue to starve themselves and the amount of fat in the body continues to decrease to the minimum, so it's on menstrual conditions usually stop His behavior is often hyperactive. Experience has problems with weight make it always feeling fat. This encourages diet uncontrolled, excessive exercise and ended up suffering from bulimia.

Anorexic sufferers think that skin and flesh as fat which must be eliminated. In the absence fat in the patient's body, causing sitting and lying down is an activity uncomfortable activities (because too thin), sufferers are usually also difficult to sleep. Furthermore, the patient gradually withdrew from friends and family, they prefer to be alone. Anorexia sufferers often experience a drop in pressure blood, weakened breath, in adult women menstruation has stopped, in girls who have growing up may not start having menstruation at all, gland the thyroid

\section{CONCLUSION}

From the research results, it can be concluded that there is a relationship between the tendency of anorexia nervous disorders and the tendency of body dysmorphic disorders. Body image is the feeling, experience, attitude and evaluation that a person has regarding his body which includes body shape, body size and body weight which leads to a physical appearance that can be positive or negative. Imaging a slim body is still a woman's dream. This phenomenon is feared to double the cases of anorexia. Because, there is a tendency for women to use all means to have an ideal body. Patients should be treated immediately, if it is protracted it is more difficult to recover quickly. Even though the condition of your body in the mirror is so thin, the mind still says that you are still fat. This is indeed quite difficult to recover from, especially since this has happened for quite a long time. Many anorexics who are hospitalized in a very sad condition have only bones covered with skin, but they still feel fat.

\section{REFERENCES}

1. Cash, T. F \& Pruzinsky, T. 2002. Body image: A handbook of theory, research and clinical practice. Guilford Press.

2. Goel N, Stunkard AJ, Rogers NL, Van Dongen HPA, Allison KC, O'Reardon JP, et al. Circadian rhythm profiles in women wit night eating syndrome. J Biol which regulates growth gradually disappears. Dry skin, hair and nails become brittle and easy broken.

Along with that sufferers often complain dizziness (due to the work of periodic contractions hull wall and grind motion food in the intestine keeps going and when it happens protruding can cause stomach ulcers and colitis), which is cold due to loss of body fat, it's hard defecate (because it is not there more residual due to absence sufficient food), limp (that energy produced from food), and happened joint swelling. Naturally on at that instant a lot of hair grew on body surfaces including on the face and with such chemical changes terrible causes sufferers easy had heart disease. Sufferers should be treated immediately, when it's protracted it's harder to recovered immediately. Even though the condition of your body in the mirror is so thin, the mind still says that you are still fat. It is indeed quite difficult to recover, moreover this has happened in the long run its been a long time. Lots anorexia sufferers who are treated at home ill in a very sad condition his body was only bones clad in skin, however still he felt fat. ${ }^{12}$

Mortality is a risk in patients with AN, due to attempted suicide or complications from a chronic eating disorder. The risk of mortality has decreased over the past 25 years with treatment and early identification of AN. Approximately 25\% remain symptomatic. The healing process is long lasting, it can be 2 years from the onset of AN.

There are also patients with AN switching to other types of eating disorders, such as bulimia nervosa and binge-eating disorder, suggesting a link between these eating disorders. ${ }^{12,13}$ Eating disorders can be fatal as a result of continuing nutritional deficiencies. Patients with eating disorders sometimes try to kill themselves or avoid social activities. It should be emphasized that this disorder not only interferes with eating behavior, but also has consequences on the patient's physical, psychological and social aspects. ${ }^{11}$
Rhythms. 2009;24:85-94.

3. Sadock, B. J., Ahmad, S., \& Sadock, V. A. (2018). Kaplan \& Sadock's Pocket Handbook of Clinical Psychiatry. Philadelphia: Lippincott Williams \& Wilkins.

4. American Psychiatric Association. (2000). Diagnostic and statistical manual of menta disorders : DSM-IVTR. 4th ed..Washington, DC: American Psychiatric Association.

5. Kusumajaya, A. N., Wiardami, N. \& Juniarsama, I., 2008 Persepsi Remaja terhadap Body Image (Citra Tubuh) Kaitannya dengan Pola Konsumsi Makan dan Status Gizi. Jurnal Skala Husada, Volume 5.

6. Academy for Eating Disorder. Prevalence of eating disorders, 2006. Austria: Academy for Eating Disorder

7. Kurniawan, MY \& Briawan, D. 2014. Persepsi tubuh dan gangguan makan pada remaja perempuan. Jurnal Gizi dan Pangan. 9(2) : 01-02.

8. Siregar RUP. Hubungan Citra Tubuh Dengan Gangguan Makan Pada Remaja Putri Masa Pubertas. Jurnal Program Studi Kesehatan Masyarakat Universitas Airlangga. 2016; 1(1):01-02.

9. Dwintasari AM. Hubungan persepsi tubuh (body image) dengan gangguan makan (eating disorder) pada mahasiswi fakultas ilmu kesehatan universitas muhammadiyah Surakarta. Universitas Muhammadiyah Surakarta, 2018

10. Adriani dan Wirjatmadi. 2012. Peranan Gizi dalam Siklus Kehidupan. Kencana. Jakarta.

11. Tsuboi, K. 2005. Eating Disorders in Adolescence and their Implications. Japan of Japan Medical Association 48 (3): 123-129

12. National Collaborating Centre for Mental Health (UK). 
Eating Disorders: Core Interventions in the Treatment and Management of Anorexia Nervosa, Bulimia Nervosa and

Related Eating Disorders. Leicester (UK): British Psychological Society (UK); 2004. (NICE Clinical

Guidelines, No. 9.) National Collaborating Centre for Mental Health staff. Available from: https://www.ncbi.nlm.nih.gov/books/NBK49324/

13. Garner, David. 2002. Body image and anorexia nervosa. $\{295-$

303\},https://www.researchgate.net/publication/260898428 _Body_image_and_anorexia_nervosa 